\title{
An evaluation of the effect on lower extremity fracture healing of collagen-based fusion material containing 2 different calcium phosphate salts: An experimental rat model
}

\author{
Atıf Mehmet Erol Aksekilii,A-B,D,F, Yusuf Polatt ${ }^{2, A-C}$, Kaan Yüksel ${ }^{3, A-C}$, Mehmet Asiltürk, ${ }^{4, B, D, F}$, \\ Mahmut Uğurlu ${ }^{1, E, F}$, Halil Kara ${ }^{1, B, C}$, Evrim Öztürk Önder ${ }^{5, A, B}$, Nihat Tosun ${ }^{1, E, F}$ \\ ${ }^{1}$ Department of Orthopedics and Traumatology, Faculty of Medicine, Ankara Yıldırım Beyazıt University, Turkey \\ 2 Department of Orthopedics and Traumatology, Çankırı Public Hospital, Turkey \\ ${ }^{3}$ Department of Orthopedics and Traumatology, Dr. Nafiz Korez Sincan Public Hospital, Turkey \\ ${ }^{4}$ Department of Orthopedics and Traumatology, Ankara Atatürk Training and Research Hospital, Turkey \\ ${ }^{5}$ Department of Pathology, Ankara Dışkapı Yıldırım Beyazıt Traning and Research Hospital, Turkey \\ A - research concept and design; B - collection and/or assembly of data; $C$ - data analysis and interpretation; \\ $D$ - writing the article; $E$ - critical revision of the article; $F$ - final approval of the article
}

Address for correspondence

Mehmet Asiltürk

E-mail:mehmetasilturk@gmail.com

Funding sources

None declared

Conflict of interest

None declared

Received on December 19, 2017

Reviewed on January 14, 2018

Accepted on May 5, 2018

\begin{abstract}
Background. Collagen-based synthetic bone grafts which contain tricalcium phosphate (TCP) and hydroxyapatite (HA), and collagen-based synthetic bone grafts containing only TCP have some advantages compared to autografts. Therefore, these grafts are frequently used to fill bone defects and pseudoarthrosis.

Objectives. The aim of this study was to evaluate and compare the clinical, radiological and histopathological effects of TCP-HA and TCP alone + Type-1 collagen in healing lower extremity fractures in a pseudoarthrosis model in rat femurs.

Material and methods. A total of 36 female Wistar rats were randomly separated into 4 groups. Group 1 $(n=10)$ was the control group. A femur pseudoarthrosis model was created in Groups 2,3 and 4 . On the $90^{\text {th }}$ day after the $1^{\text {st }}$ surgery in Group $2(n=10)$, TCP-HA + Type-1 collagen was applied, in Group $3(n=10)$, TCP alone + type-1 collagen was applied, and in Group 4 ( $n=6$, the placebo group), saline solution was applied. Fixation was performed with an intramedullar pin. After 60 days and clinical and radiological scoring, all animals were sacrificed and a histopathological evaluation of the pseudoarthrosis areas was conducted.

Results. In all the clinical, radiological and histopathological measurements used in the evaluations of the differences between the groups, a higher rate of union was determined in Group 2 (TCP-HA). No significant difference was determined between Group 3 and Group 4 in terms of union rates.
\end{abstract}

Conclusions. The clinical, radiological and histopathological results of this study showed that TCP alone was less effective than TCP-HA in the union of a femur pseudoarthrosis model in rats. The reason for this difference was considered to be hydroxyapatite (HA).

Keywords: rats, collagen, synthetic bone graft, bone healing, pseudoarthrosis

DOI

10.17219/acem/90766

Copyright

Copyright by Author(s)

This is an article distributed under the terms of the

Creative Commons Attribution Non-Commercial License

(http://creativecommons.org/licenses/by-nc-nd/4.0/) 


\section{Introduction}

As an increasing number of fractures and non-union cases are encountered in orthopedic practice, along with developments in the implants and biomaterials used, there is ongoing research into achieving more rapid union with less surgical damage. In the treatment of bone defects which occur during reconstructive procedures such as trauma, osteomyelitis and arthroplasty revision surgery, increasingly frequent use of bone grafts and substances that can be used instead of bone is observed. ${ }^{1}$ Of the grafts used, autografts taken from the iliac wing are the gold standard, with osteoinductive, osteogenesis and osteoconductive properties. However, this procedure has disadvantages, including increased morbidity in the patient, prolonged operating time, limitations to the extent it can be used, and pain in the donor site. Great care is necessary in the use of allograft because of a possibility of infection and immunological reactions. ${ }^{2,3}$

Bone tissue engineering has presented solutions for the production of new bone tissue that has all the necessary functional and mechanical properties at a sufficient level, considering the costs and the risks involved in the use of autografts and allografts. As most of the products that have been developed are at the experimental stage, their clinical use is still limited. Scientific studies contribute to the effective and safe use of these products in practice. ${ }^{4}$

From the spongeous structure of collagen, which is a natural protein in the body, a membrane form is obtained by physically attaching calcium phosphate salts and/or hydroxyapatite (HA) crystals in nano dimensions to this structure, resulting in synthetic grafts for use in bone defects and fracture healing. MasterGraft Putty ${ }^{\circledR}$ (Medtronic Sofamor Danek, Memphis, USA) is a biomaterial designed for filling bone defects; it is highly porous and bioabsorbable; it contains cruciate ligament type-1 collagen, tricalcium phosphate and HA. Debone ${ }^{\circledR}$ (Desu Medical, Ankara, Turkey) is another biomaterial designed for filling bone defects; it contains cruciate ligament type-1 collagen and only tricalcium phosphate.

The aim of this study was to evaluate with clinical, radiological and histopathological measurements the effects on lower extremity fracture healing of MasterGraft Putty and Debone by creating a pseudoarthrosis model in rat femurs, and to compare the efficacy of these products with each other and with a placebo.

\section{Material and methods}

Prior to starting the study, approval was granted by the Local Ethics Committee (decision dated June 3, 2014). All procedures were carried out in accordance with the Research Animal Laboratory Local Ethics Committee regulations. The rats were obtained from the Experimental Animals Laboratory, Ankara, Turkey, where they had been bred.

\section{Animals}

The study included 36 outbred, conventional female Wistar rats, aged 8-10 weeks, each weighing $300 \mathrm{~g}( \pm 10 \%)$. The rats were housed in cages constructed of plastic in the lower half and wire in the upper, with easy access to food and water. The cages were lined with sawdust and cleaned 4 times a week. All the rats were housed in single cages at room temperature $\left(23^{\circ} \mathrm{C}\right), 60 \%$ humidity and a 12-hour light-dark cycle with $100 \%$ air change 12 times per hour. Throughout the study the animals had free access to a pellet diet and refined tap water provided in an autoclavable Makrolon bottle (Optima, Balıkesir, Turkey).

The 36 rats were randomly separated into 4 groups. Group 1 ( $\mathrm{n}=10$ ) was the control group with no surgical procedure applied; in Group $2(\mathrm{n}=10)$ MasterGraft Putty was applied to the femur pseudoarthrosis model; in Group $3(\mathrm{n}=10)$ Debone was applied to the femur pseudoarthrosis model; and Group $4(n=6)$ was the placebo group, with saline solution applied.

\section{Surgical procedure}

\section{First surgical intervention}

The surgical pseudoarthrosis model was created as described in previous studies. ${ }^{5}$ With the exception of the rats in Group 1, anesthesia of $10 \mathrm{mg} / \mathrm{kg}$ of $10 \%$ ketamine + $100 \mathrm{mg} / \mathrm{kg}$ of $2 \%$ xylazine was administered intraperitoneally to all rats. After the preparation of the rats in a lateral position, the left lower extremity was shaved. Following disinfection with a $10 \%$ polyvinylpyrrolidone-iodine complex (Batticon ${ }^{\circledR}$; Adeka, Samsun, Turkey), a femoral diaphyseal osteotomy was performed, a fascia lata flap was taken and fixed to the proximal and distal fracture lines with 3-0 nylon sutures, and then all the layers were closed in order. Oxytetracycline hydrochloride aerosol (Neo-CafSpray ${ }^{\circledR}$; Intervet, Aprilia, Italy) was applied to the suture line (Fig. 1).

In the postoperative follow-up, analgesia of $0.05 \mathrm{~mL} /$ day of meloxicam (Maxicam ${ }^{\circledR}$; Sanovel, Istanbul, Turkey; $5 \mathrm{mg} / \mathrm{ml}$ ) was applied subcutaneously with a $25 \mathrm{G}$ syringe for 3 days. As a prophylactic antibiotic, $50 \mathrm{mg} / \mathrm{kg}$ of amoxicillin (Amoxycure LA ${ }^{\circledR}$; Provet Veteriner Ürünleri A.Ş., Istanbul, Turkey; $150 \mathrm{mg}$ ) was applied intramuscularly with a $21 \mathrm{G}$ syringe for 3 days.

The rats were checked daily by a veterinarian experienced in the field of laboratory animals and the cages were cleaned 4 times per week. In the $1^{\text {st }}$ week after the $1^{\text {st }}$ surgical procedure, 2 rats from Group 2 and 2 rats from Group 3 died; thus, the study continued with 10 animals in Group 1, 8 in Group 2, 8 in Group 3, and 6 in Group 4. At this stage the 32 rats were labeled C, M, D, and $\mathrm{P}+$ number, corresponding to Groups 1, 2, 3, and 4 .

On the $90^{\text {th }}$ day after the $1^{\text {st }}$ surgical procedure, all the rats underwent claudication scoring and direct radiographs to check whether union had occurred. Two rats 
were selected at random from each of Groups 2, 3 and 4 (M-4, M-5, D-1, D-2, P-2, P-5), and were euthanized with an anesthesia overdose $(4 \mathrm{~mL}$ of $2.5 \%$ sodium pentothal, intraperitoneally) and the lower left extremity was amputated. A sample was taken from the pseudoarthrosis tissue and histopathological evaluation of the tissue confirmed the pseudoarthrosis model.

\section{Second surgical intervention}

With the exception of the control group, the $2^{\text {nd }}$ surgical procedure was applied to the remaining 16 rats 90 days after the $1^{\text {st }}$ surgery. With a longitudinal entry incision from the lateral femur, fibrotic tissues around the fracture were cleaned. The proximal and distal bone medulla was opened by rotating a $27 \mathrm{~mm} \times 8 \mathrm{G}$ hypodermic needle. In Group 2, MasterGraft Putty was prepared by wetting with sterile water, and then applied to encircle the pseudoarthrosis line $360^{\circ}$, according to the anatomy of the femur. Following the same steps, Debone was applied to Group 3 (Fig. 2). Saline solution only was applied to Group 4. Then the femur fractures of all rats were fixed with an intramedullar pin including 50-60\% of the medulla. Finally, the layers were closed in order.

At 3 days before and 60 days after the $2^{\text {nd }}$ procedure, clinical evaluations of all rats were conducted using a claudication scoring system that was developed for use in dogs and later adapted for other animals (Table 1$){ }^{6}$

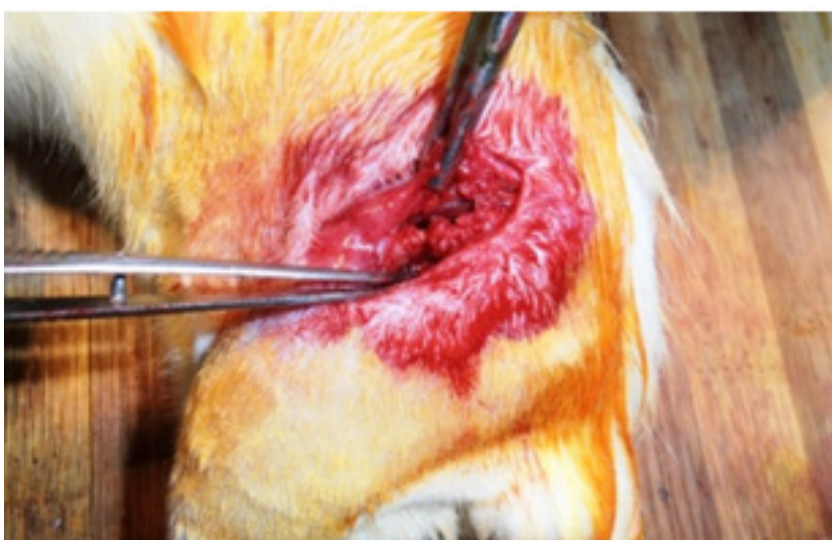

Fig. 1. First surgical procedure

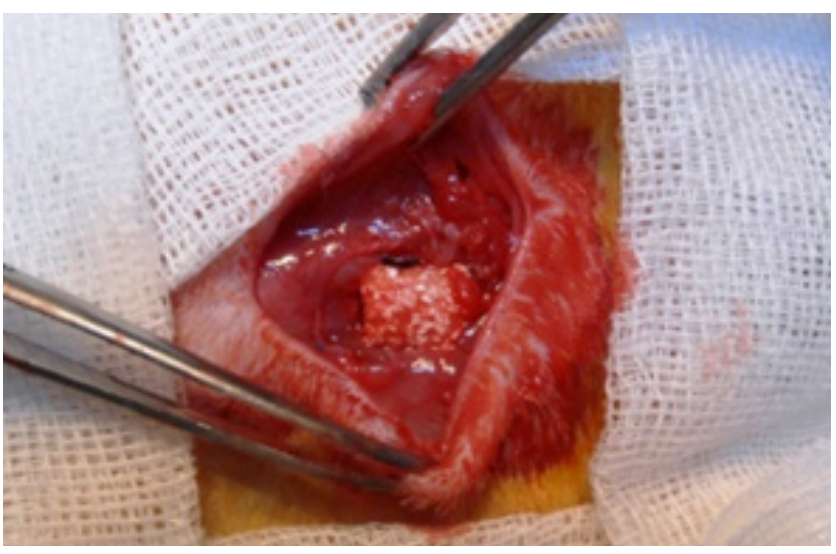

Fig. 2. Application of the graft during the $2^{\text {nd }}$ surgical procedure
Table 1. Claudication scoring system

\begin{tabular}{|l|c|}
\hline Degree & Criterion \\
\hline 1 & $\begin{array}{r}\text { absence of claudication, full limb support when the animal } \\
\text { was in a standing position or during physical activities } \\
\text { mild claudication after exercise or prolonged decumbency }\end{array}$ \\
\hline 3 & $\begin{array}{r}\text { sporadic claudication when walking or running and weight } \\
\text { relief on the operated limb, even in a standing position }\end{array}$ \\
& $\begin{array}{r}\text { constant claudication when walking and lack } \\
\text { of limb support when running; incomplete support } \\
\text { in the orthostatic position }\end{array}$ \\
\hline 5 & full or absent support during physical activities \\
& or in a standing position \\
\hline
\end{tabular}

At 3 days before and 30 and 60 days after the $2^{\text {nd }}$ surgical procedure, radiological evaluations of all rats were performed using $\mathrm{x}$-rays, with modifications of a radiological scoring system that had previously been used on rat tibias. ${ }^{7}$ For each rat the number of cortices showing union on anteroposterior and lateral radiographs was noted. The number of cortices showing union was defined as $0=$ no union, 1 or $2=$ partial union, and 3 or $4=$ full union (Table 2 ).

Table 2. Radiological scoring system

\begin{tabular}{|l|c|}
\hline \multicolumn{1}{|c|}{ Degree of union } & Number of cortices showing union \\
\hline Nonunion & 0 \\
\hline Partial union & 1 or 2 \\
\hline Union & 3 or 4 \\
\hline
\end{tabular}

Sixty days after the $2^{\text {nd }}$ surgery, all the remaining rats were sacrificed using high-dose anesthesia, the lower left extremity was amputated and the intramedullar pins were removed. Samples were taken for histopathological examination from the osteotomized femur and the pseudoarthrosis tissue. The prepared materials were fixed in $10 \%$ formalin and then embedded in paraffin blocks. Sections $4 \mu \mathrm{m}$ in thickness were cut from the blocks and stained with hematoxylin and eo$\sin (\mathrm{HE})$. The sections were examined under a microscope and photomicrographs were obtained. The healing tissue in the fracture region was evaluated histopathologically using the scale recommended by Huo et al. (Table 3 ). ${ }^{8}$

Table 3. Histopathological evaluation scale recommended by Huo et al. ${ }^{8}$

\begin{tabular}{|l|r|}
\hline Score & Histopathological features of healing tissue \\
\hline 1 & fibrous tissue \\
\hline 3 & fibrous tissue containing a small amount of cartilage \\
\hline 4 & equal ratio of fibrous and cartilage tissue \\
\hline 5 & cartilage tissue containing a small amount of fibrous tissue \\
\hline 7 & cartilage tissue containing a small amount of immature bone \\
\hline 8 & immature bone tissue containing a small amount of cartilage \\
\hline 10 & immature bone tissue combined with fragments \\
\hline
\end{tabular}




\section{Statistical analysis}

The statistical analyses and calculations were carried out using SPSS v. 21.0 software (IBM Corp., Armonk, USA). The claudication and histopathological results obtained were stated as median (minimum-maximum) values and the radiology results were stated as numbers. The comparisons of the claudication and histopathological results of the 3 groups apart from the control group were made with the Kruskall-Wallis test. Paired comparisons of the groups were made with the Mann-Whitney U test with Bonferroni correction. The difference between the preoperative claudication results and the claudication results 60 days after the $2^{\text {nd }}$ surgery within the groups was determined with the Wilcoxon test. For the radiology results, 10,000 repetitions of a Monte Carlo simulation of the Pearson's $X^{2}$ test provided the result. To determine the origin of the difference, paired groups were compared using the same test. A value of $\mathrm{p}<0.05$ was considered statistically significant.

\section{Results}

After the $1^{\text {st }}$ surgical procedure, a total of 4 rats -2 from Group 2 and 2 from Group 3 - died because of anesthesiarelated complications. These complications were consistent with the type and rate of complications published in previous studies by other laboratories. ${ }^{9}$

In Group 1, all the claudication results were evaluated as Grade 1 . When the claudication results before the $2^{\text {nd }}$ surgery were examined, all 22 rats in Groups 2, 3 and 4 were evaluated as median grade 3 (range: $2-5$ ). No statistically significant differences were determined between these 3 groups in terms of the claudication scores before the $2^{\text {nd }}$ surgical procedure $\left(x^{2}=0.095, p=0.953\right)$. The claudication results of 16 rats in all the groups 60 days after the $2^{\text {nd }}$ surgical procedure were similar $\left(\chi^{2}=4.562, \mathrm{p}=0.102\right)$.

In the radiological evaluation 90 days after the $1^{\text {st }}$ operation, it was confirmed that pseudoarthrosis had occurred in the model used in the Group 2, 3 and 4 rats.

Radiological evaluations were performed on a total of 16 rats 30 and 60 days after the $2^{\text {nd }}$ surgical procedure. No difference was observed between the groups in the 30 -day postoperative results $(\mathrm{p}=0.116)$. On the $60^{\text {th }}$ postoperative day, in Group 2 full union was observed in 5 rats and partial union in 1 rat; in Group 3, full union was seen in 1 rat and partial union in 5 rats; in Group 4, full union was seen in 1 rat, partial union in 1 rat and nonunion in 2 rats (Fig. 3). The rate of union in Group 2 was determined to be significantly higher than in Groups 3 and 4 $(\mathrm{p}=0.004)$. Group 3 showed no superiority over Group 4 .

The fact that bone union had not occurred was confirmed with histopathological evaluations of 6 rats -2 each from Groups 2, 3 and 4 - sacrificed 90 days after the $1^{\text {st }}$ surgery.

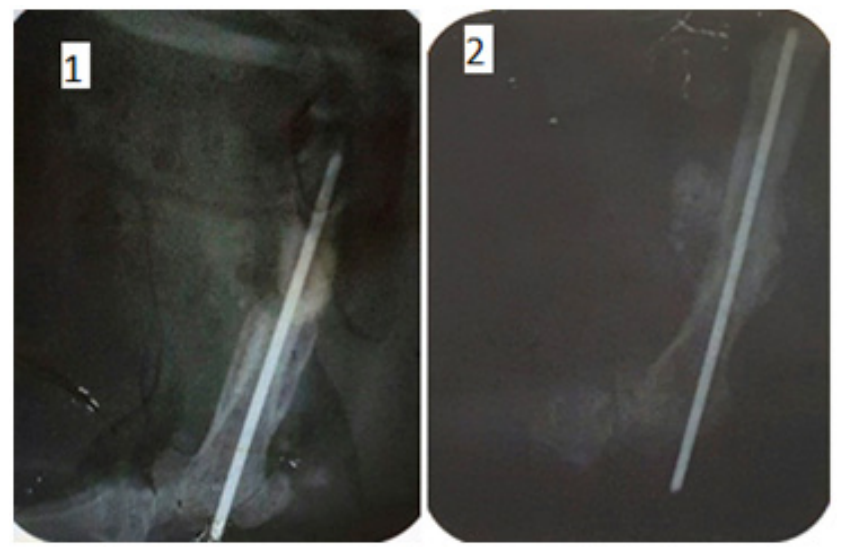

Fig. 3.1 - the pseudoarthrosis line seen immediately after the $2^{\text {nd }}$ surgical procedure; 2 - union of the fracture line using MasterGraft Putty seen at 60 days after the $2^{\text {nd }}$ surgical procedure

On the $60^{\text {th }}$ postoperative day, the histopathology results were determined as median 5.5 (range: 4-7) in Group 2, median 4.5 (range: $3-7$ ) in Group 3 and median 3 (range: 1-4) in Group 4 (Fig. 4).

In the comparison of the groups according to the histopathological results, a significantly higher rate of union was found in Group 2 compared to Group 4 ( $\mathrm{p}<0.05$ ). No statistically significant difference was determined between Group 3 and Groups 2 and 4 (p > 0.05).

\section{Discussion}

Although there is no consensus on which method is the best in the current surgical treatment of pseudoarthrosis, there are many treatment options. Various methods, such as vascularized bone graft, cancellous autograft, bone morphogenetic protein (BMP), transforming growth factor (TGF), ultrasound, shock waves, and electromagnetic fields are used to provide union. ${ }^{10}$ Of these, composite synthetic grafts offer an alternative combining osteogenesis, osteoconduction and osteoinduction as potentially effective and controlled combinations without the disadvantages created by autograft, and many ceramic composites have been developed for this purpose. ${ }^{11,12}$

Wistar rats were selected for this study because their hind extremities contain a bone structure covered with a large muscle mass comparable to that in humans, which is resistant to infection and can be easily used because of its small size. Furthermore, the hypertrophic pseudoarthrosis model formed following femoral diaphyseal osteotomy has been observed to mimic human conditions at an appropriate level and rats have been proven to create a useful model for examination of the in vivo effects of locally placed osteoinductive agents in addition to intramedullary nailing. ${ }^{13}$

In studies of fracture healing in rats, different techniques have been used, such as internal fixation, external fixation and intramedullary nailing. ${ }^{14,15}$ Although nailing is accepted as the gold standard treatment method in long bone 
diaphyseal fractures, it is the callus formation resulting from micromovement in the osteotomy area that leads to fracture healing. ${ }^{16}$ With the placement of osteoinductive agents, fracture healing in the osteotomy site can be misinterpreted as the presence of callus. In addition, the application of rigid fixation with plating is very difficult in rats. ${ }^{13}$ Furthermore, the application of HA and tricalcium phosphate-based ceramics along with fixed plates or external fixators for segmentary losses in the long bones has been shown to prevent mechanical stimuli, which are necessary for healing of the defective area. ${ }^{17,18}$

In cases of bone defects or nonunion, successful results have been obtained with the use of osteoconductive scaffolds designed to support osteointegration with osteogenic substances. ${ }^{19}$ When designing the ideal scaffold, the aim is to obtain the mechanical properties needed to support the fracture line with a particular 3-dimensional structure, an osteoconductive matrix suitable for osteogenic cells, and (instead of fusion) a rate of matrix resorption that will be compatible with progressive bone replacement. If the scaffold is not sufficiently robust, it cannot undertake the skeletal function in the defective area and the success of the graft will be reduced, with early or late resorption of the scaffold. ${ }^{20}$
Synthetic materials used to fill bone defects are HA, beta-tricalcium phosphate $(\beta-\mathrm{TCP})$ or $\mathrm{HA} / \beta$-TCP biphasic composite. As the resorption of HA takes 10 years, it is accepted as a non-resorbable substance. The solubility of $\beta$-TCP is very close to the mineral part of bone, is eroded with osteoclastic activity as in necrotic bones and is resorbed within 1 to 2 years in vivo. Biphasic calcium phosphate (BCP) is between HA and $\beta$-TCP in terms of the resorption rate. If there is a high ratio of $\beta$-TCP, then BCP is resorbed more quickly. ${ }^{21}$

The biocompatibility of ceramics used as grafts is very important to minimize complications that may develop in the future. Particles that emerge after the erosion of the biomaterials create inflammation and bone resorption as negative effects on the long-term success. Material debris $<2 \mathrm{~mm}$ in size create osteolysis as a result of erosion, and these debris lead to a cellular reaction in the surrounding cytokines as a result of phagocytosis. ${ }^{22}$ In the current study, although large and small HA and TCP particles that had broken off the ceramic wear were encountered, especially in the areas close to the K-wire and in sections close to the contact surface with the femur, no phagocytes were found in the examined sections. This shows the low capacity of the HA and TCP materials to form an inflammatory response.

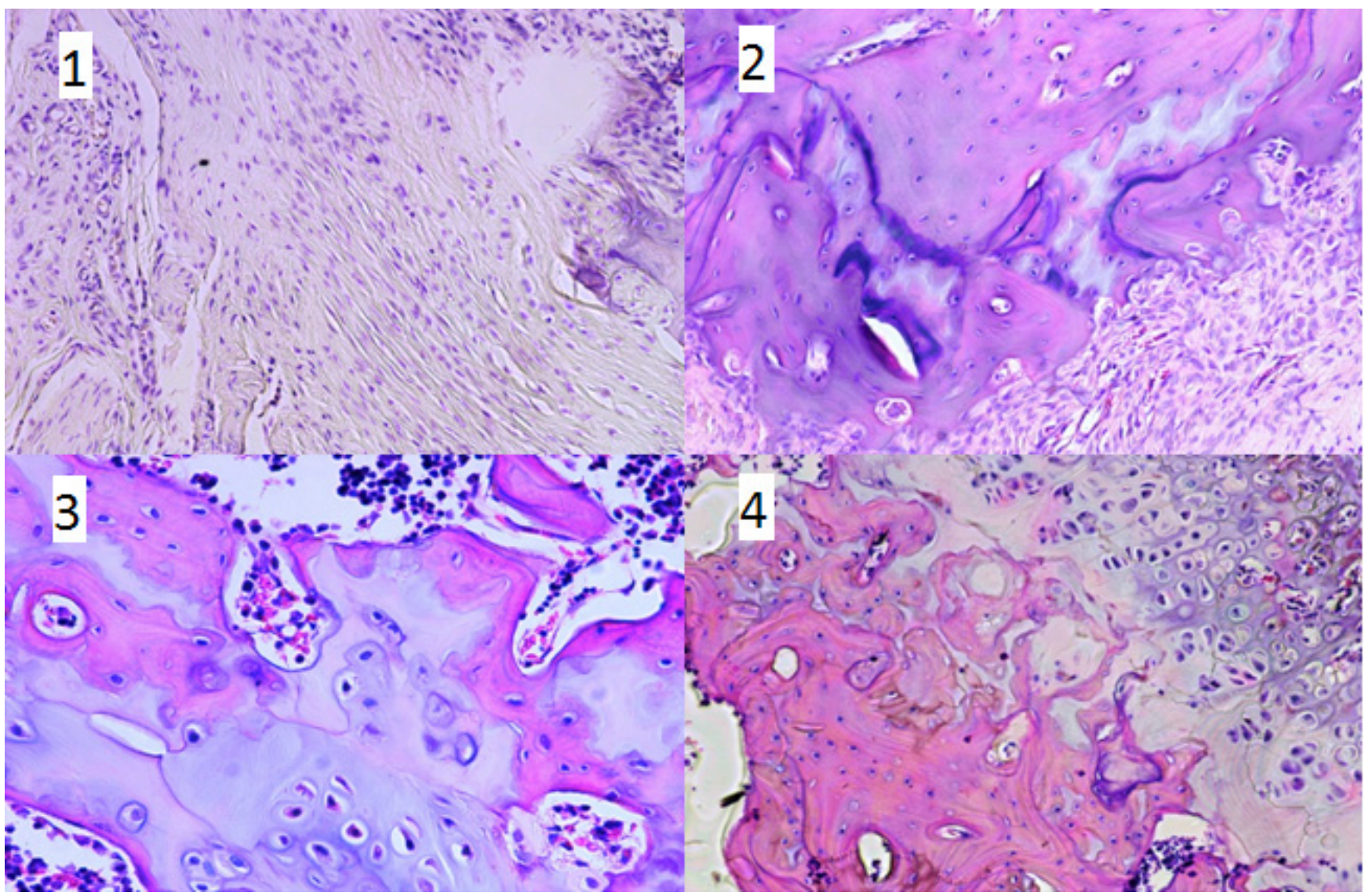

Fig. 4. 1 - photomicrograph of the femur pseudoarthrosis region (light microscope), fibrous tissue filling the healing line (histological score 1), hematoxylin and eosin (HE) staining, magnification $\times 400 ; 2$ - photomicrograph of the femur pseudoarthrosis region (light microscope), cartilage tissue containing a small amount of fibrous tissue in the healing line (histological score 4), HE staining, magnification $\times 200 ; 3$ - photomicrograph of the femur pseudoarthrosis region (light microscope), cartilage tissue containing a small amount of immature bone (histological score 6), HE staining, magnification $\times 200 ; 4$ - photomicrograph of the femur pseudoarthrosis region (light microscope), bone and cartilage tissue filling the healing line (histological score 7), HE staining, magnification $\times 200$ 
Type-1 collagen is an appropriate structure for the support, growth and matrix accumulation of several cell types and has been seen to have high biocompatibility with weak antigenicity. In addition, in bioreactors applied with moderate perfusion or hydrostatic fluid pressure, type-1 collagen has been shown to increase the histogenicity of cells in collagen sponges. Collagen-based biomaterials with calcium phosphate and HA as basic components have a long history in multiple clinical applications before they were used as bone graft materials. ${ }^{23,24}$

MasterGraft Putty is a biomaterial containing 85\% $\beta$-TCP and $15 \%$ HA with type-1 collagen, the efficacy of which has been shown in spinal fusion in previous studies. ${ }^{25}$ The biphasic structure provides a completely osteoconductive graft with a structure similar to that found naturally within the bone. ${ }^{21,26}$ Debone is a biomaterial containing $\beta$-TCP with type-1 collagen that does not contain HA.

When the claudication results were evaluated in the current study, no difference was determined between the groups before the $2^{\text {nd }}$ surgical procedure. In the evaluation conducted 60 days after the $2^{\text {nd }}$ surgical procedure, although the claudication results of Group 2 were at a lower grade, the difference was not statistically significant. However, a statistically significant difference was determined between the preoperative and postoperative claudication scores in Group 2. In the other 2 groups, the differences between the preoperative and postoperative scores were not found to be statistically significant. As a result of this difference, the efficacy in Group 2 can be considered greater. In the radiological evaluation, no significant difference was determined between the groups 30 days after the $2^{\text {nd }}$ surgical procedure, but in the evaluation on the $60^{\text {th }}$ day, the rate of union in Group 2 was determined to be significantly higher than that of Groups 3 and 4. In the histopathological evaluation, the results in Group 2 were observed to be better than those in Group 3, and Group 3 was better than Group 4. However, statistically, only Group 2 was superior over Group 4.

When all these results were evaluated, the bone union in Group 2 was seen to be superior over that in Group 3. It was concluded that as Group 2 contained HA, unlike Group 3, this had an effect on the results. It was thought that the reason that there was no significant difference between the results in Group 3 and Group 4 was that Group 3 contained only $\beta$-TCP, which was quickly resorbed by the body.

In a study by Smucker et al. of a rabbit posterolateral fusion model with 3 groups - autograft, MasterGraft Putty 25/75 autograft and MasterGraft Putty 50/50 autograft the results of the MasterGraft Putty 50/50 autograft group were no worse than those of the group where autograft only was used, and by some criteria obtained better results. It was recommended that the use of autograft could be reduced in this way. ${ }^{25}$ In contrast, in a rabbit study by Miller et al. using 2 different ceramic grafts, it was reported that they made no significant contribution to the fusion rates compared to the use of autograft alone. ${ }^{19}$
Oryan et al. examined the effect on healing of a chitosan/gelatin/platelet gel enriched with TCP alone, HA alone or a TCP-HA mixture, in a radial bone defect created in rats. The best result was obtained in the graft enriched with the TCP-HA mixture, and it was reported that it could be used in place of autograft. ${ }^{27}$

There were some limitations to the current study. To examine the effects of collagen and bioceramics on fracture healing in more detail, a greater number of subjects are needed, and biomechanical and biochemical examinations should be added. Although animal models shed a significant amount of light on the subject, there is a need for further investigation of the biotechnology of these products in a clinical setting.

\section{Conclusions}

The results of this study showed that in a rat femur pseudoarthrosis model, MasterGraft Putty was effective in bone healing according to clinical, radiological and histopathological criteria, while Debone was not effective to the same degree. The ceramics used were seen to be biocompatible with bone cells. The application of long-term implants containing HA and $\beta$-TCP is promising. It can be concluded that with the support of bioelements which will provide an osteogenic contribution and by optimizing the resolution time with HA, ceramic composites have the potential to be used safely in the future for the healing of segmentary bone losses in place of autografts and allografts.

\section{References}

1. Greenwald AS, Boden SD, Goldberg VM, et al.Khan Y, Laurencin CT, Rosier RN; American Academy of Orthopaedic Surgeons; The Committee on Biological Implants. Bone-graft substitutes: fFacts, fictions, and applications. JBJS. J Bone Joint Surg Am. 2001;83-A(Suppl 2 Pt 2):S98-S103.

2. Gupta AR, Shah NR, Patel TC, et al. Perioperative and long-term complications of iliac crest bone graft harvesting for spinal surgery: A quantitative review of the literature. Int Med J. 2001;8(3):163-166.

3. Szpalski M, Gunzburg R. Applications of calcium phosphate-based cancellous bone void fillers in trauma surgery. Orthopedics. 2002;25(5 Suppl):S601-S609.

4. Shadjou N, Hasanzadeh M. Bone tissue engineering using silicabased mesoporous nanobiomaterials: Recent progress. Mater Sci Eng CMater Biol Appl. 2015;55:401-409.

5. Ferreira ML, Silva PC, Pereira LdPM, et al. Experimental model in rats for the development of pseudoarthrosis [in Portuguese]. Rev Col Bras Cir. 2009;36(6):514-518.

6. Muzzi L, Rezende C, Muzzi R, et al. Ruptura do ligamento cruzado cranial em cães: fisiopatologia e diagnóstico. Clin Vet. 2003;46(1):32-42.

7. Schmidmaier G, Wildemann B, Melis B, et al. Development and characterization of a standard closed tibial fracture model in the rat. European Journal of Trauma. 2004;30(1):35-42.

8. Huo MH, Troiano NW, Pelker RR, Gundberg CM, Friedlaender GE. The influence of ibuprofen on fracture repair: Biomechanical, biochemical, histologic, and histomorphometric parameters in rats. J Orthop Res. 1991;9(3):383-390.

9. Green C, Knight J, Precious S, Simpkin S. Ketamine alone and combined with diazepam or xylazine in laboratory animals: a 10 year experience. Lab Anim. 1981;15(2):163-170.

10. Ferreira ML, Silva PC, Silva LHA, et al. Heterologous mesenchymal stem cells successfully treat femoral pseudarthrosis in rats. J Transl Med. 2012;10:51. 
11. Friedenstein A, Piatetzky-Shapiro I, Petrakova K. Osteogenesis in transplants of bone marrow cells. J Embryol Exp Morphol. 1966;16(3):381-390.

12. Hoffmeister BK, Johnson DP, Janeski JA, et al. Ultrasonic characterization of human cancellous bone in vitro using three different apparent backscatter parameters in the frequency range $0.6-15.0 \mathrm{MHz}$. IEEE Trans Ultrason Ferroelectr Freq Control. 2008;55(7):1442-1452.

13. Russell G, Tucci M, Conflitti J, et al. Characterization of a femoral segmental nonunion model in laboratory rats: Report of a novel surgical technique. J Invest Surg. 2007;20(4):249-255.

14. Hietaniemi K, Peltonen J, Paavolainen P. An experimental model for non-union in rats. Injury. 1995;26(10):681-686.

15. Kokubu T, Hak DJ, Hazelwood SJ, Reddi AH. Development of an atrophic nonunion model and comparison to a closed healing fracture in rat femur. J Orthop Res. 2003;21(3):503-510.

16. Grundnes $\mathrm{O}$, Reikerås $\mathrm{O}$. Mechanical effects of function on bone healing: Nonweight bearing and exercise in osteotomized rats. Acta Orthop Scand. 1991;62(2):163-165.

17. Petite $\mathrm{H}$, Viateau V, Bensaid W, et al. Tissue-engineered bone regeneration. Nat Biotechnol. 2000;18(9):959-963.

18. Tiedeman JJ, Connolly JF, Strates BS Lippiello L. Treatment of nonunion by percutaneous injection of bone marrow and demineralized bone matrix: An experimental study in dogs. Clin Orthop Relat Res.1991;268:294-302.

19. Miller CP, Jegede K, Essig D, et al. The efficacies of 2 ceramic bone graft extenders for promoting spinal fusion in a rabbit bone paucity model. Spine (Phila Pa 1976). 2012;37(8):642-647.

20. Tang ZB, Cao JK, Wen N, et al. Posterolateral spinal fusion with nanohydroxyapatite-collagen/PLA composite and autologous adiposederived mesenchymal stem cells in a rabbit model. J Tissue Eng Regen Med. 2012;6(4):325-336.

21. LeGeros RZ. Properties of osteoconductive biomaterials: Calcium phosphates. Clin Orthop Relat Res. 2002;395:81-98.

22. LeGeros RZ. Biodegradation and bioresorption of calcium phosphate ceramics. Clin Mater. 1993;14(1):65-88.

23. Glowacki J, Mizuno S. Collagen scaffolds for tissue engineering. Biopolymers. 2008;89(5):338-344.

24. Lee $\mathrm{CH}$, Singla $\mathrm{A}$, Lee $\mathrm{Y}$. Biomedical applications of collagen Int J Pharm. 2001;221(1-2):1-22.

25. Smucker JD, Petersen EB, Fredericks DC. Assessment of MASTERGRAFT PUTTY as a graft extender in a rabbit posterolateral fusion model. Spine (Phila Pa 1976). 2012;37(12):1017-1021.

26. Kalfas IH. Principles of bone healing. Neurosurg Focus. 2001;10(4):E1.

27. Oryan A, Alidadi S, Bigham-Sadegh A, Meimandi-Parizi A. Chitosan/ gelatin/platelet gel enriched by a combination of hydroxyapatite and beta-tricalcium phosphate in healing of a radial bone defect model in rat. Int J Biol Macromol. 2017;101:630-637. 